\title{
A simple cost-effective manometric respirometer: design and application in wastewater biomonitoring
}

\author{
Mohammad Shahidur Rahman • Md. Akhtarul Islam
}

Received: 31 July 2013/Accepted: 31 March 2014/Published online: 23 May 2014

(C) The Author(s) 2014. This article is published with open access at Springerlink.com

\begin{abstract}
Application of respirometric tools in wastewater engineering fields is still not getting familiarity and acceptance by academy or industry in developing countries as compared to the use of conventional biochemical oxygen demand (BOD) approach. To justify the applicability of respirometry, a low-cost respirometric device suitable for monitoring biodegradation process in wastewater has been developed. This device contains six independently operating reactors placed in a temperature control unit for the bioassay of five wastewater samples simultaneously (along with one blank). Each reactor is equipped with a magnetic stirrer for the continuous agitation of the test sample. Six manometers, linked with the individual reactors, measure the pressure and volume changes in the headspace gas phase of the reactor. Working formulae have been derived to convert the 'volume-change in gas phase' data to 'the oxygen depletion in the whole liquid-gas system' data. The performance of the device has been tested with glucose-glutamic acid standard solution and found satisfactory. Conventional BOD test and the respirometric measurements were performed simultaneously and it is found that in addition to measuring the BOD of the sample, this device gives oxygen uptake profile for further analysis to determine the biokinetic coefficients. Additionally, in some cases, following a specific test protocol, the respirometer can indirectly estimate the carbon
\end{abstract}

\section{S. Rahman ( $\square)$}

Department of Civil and Environmental Engineering, Shahjalal

University of Science and Technology, Sylhet, Bangladesh

e-mail: msr.ceesust@gmail.com

URL: https://www.sust.edu

M. A. Islam

Department of Chemical Engineering and Polymer Science,

Shahjalal University of Science and Technology, Sylhet,

Bangladesh dioxide evolved during biodegradation process for calculating respiratory activity parameter such as respiratory quotient. It is concluded that the device can be used in the laboratories associated with the activated sludge plants and also for teaching and research purposes in developing countries.

Keywords Headspace gas respirometer - Wastewater . Biokinetic coefficients · Oxygen uptake rate $\cdot$ BOD · COD · RQ

\section{Introduction}

The efficiency of an activated sludge plant depends on the ability of the biomass to mineralize biodegradable organics at a desire rate so as to meet effluent standards. The oxygen uptake, in this regard, reflects the ability of the biomass to metabolize wastewater components (Hill et al. 1998). Respirometry, which is widely used for the monitoring of oxygen uptake in different biochemical processes provides a procedure to assess the state of microbial activity and is used for the determination of the parameters of microbial kinetic models including the characterization of wastewater and activated sludge (Marsili and Tabani 2002; Young and Cowan 2004).

Respirometric technique was initiated in studying the biodegradability of wastewater as early as in 1920s. The instrument designed for the purpose is known as BarcroftWarburg device. It represents a simple system consisting of a liquid reactor connected with a manometer (Jowett 1928; Perkins 1943). The biodegradation process takes place in the liquid phase of the reactor with the consumption of oxygen. The oxygen is transferred from the gas phase to the liquid, resulting in a loss of pressure in the gas phase. This pressure-loss is monitored by the manometer. 
Respiration can be considered as a general measure of the microbial activity. It can provide a reliable and scientifically sound assessment of biodegradation criteria. For this reason, respirometry (oxygen uptake rate and/or carbon dioxide evolution rate) has been widely used as an important tool in biomonitoring fields. A wide range of respirometric protocols has been reported based either on carbon dioxide production, oxygen uptake or release of heat. The most common methods are those based on oxygen uptake (Ghosh et al. 1985; Mitz and Newman 1988). Through the years, different kinds of oxygen uptake measuring technique have become available and the respirometers have been upgraded. Commercially available or user-built respirometer systems usually fall into two major categories: (1) dissolve oxygen (DO) depletion respirometer and (2) headspace gas respirometer (Young and Cowan 2004). The first type is based on measuring DO concentration in the liquid phase by an electrochemical DO-sensor and a DO mass balance is made over the liquid phase only. The second type is based on measuring oxygen concentration in the gas phase and the oxygen balance is made over the whole gas-liquid system. Gaseous oxygen is measured by physical methods such as the paramagnetic, manometric and electrolytic methods. As the biodegradation process takes place in the liquid phase, it may seem more advantageous for analysis to acquire oxygen concentration data in the liquid phase. Measurement of oxygen in the liquid phase, however, is associated with interference from contaminants common in the liquid phase (e.g. formation of sludge film on the sensor) (Vanrolleghem 2002). For this reason, the measurement in the gas phase, to some extent, is still the preferred option. In respirometry, however, emphasis is given on the oxygen consumption measurement, the amount of carbon dioxide generated as byproduct during degradation process plays an important role in overall bioactivity monitoring test. Moreover, in headspace gas respirometry, solubility of carbon dioxide in water or its absorption by the caustic scrubber significantly affects the respirometric measurement. However, mixing rates in biodegradation test that are sufficient for meeting oxygen transfer limits certainly are sufficient to allow rapid equilibrium between dissolved and headspace gases carbon dioxide (Young and Cowan 2004).

Development of instrumentation and automation has also widened the application possibilities of respirometers in terms of the optimization and operation of wastewater treatment systems, waste management, biodegradation, and kinetic parameter studies (Logan and Wagenseller 1993; Mahendraker and Viraraghavan 1995; Wu et al. 2004; Kim and Park 2005; Roppola 2009). The respirometers can provide an effective method for quickly acquiring data for toxicity screening (Tzoris and Hall 2006), organic removal rate (Edgardo et al. 2008), sludge activity and biological process modeling (Ince et al. 2008). Thus, the technique can be a useful tool for rapid characterization of wastewater and activated sludge in every small or large activated sludge plant. In spite of the large opportunities that the respirometric technique provides, the $\mathrm{BOD}_{5}$ and $\mathrm{COD}$ are still the most widely used parameters for the monitoring of influent and effluent wastewater quality of a treatment plant in the developing country (DOE 2008; Khan et al. 2009; Panda 2011). In fact, these parameters are also the measures of oxygen consumption by the wastewater, but unlike respirometric technique they do not provide information about the biodegradation kinetics. The measurement of $\mathrm{BOD}_{5}$ is a time-consuming method and the 5-day time had been accepted rather somewhat arbitrarily and without any well-argued scientific background (Min et al. 2004). The COD-measurement, on the other hand, is rapid, but its preciseness and reproducibility depend much on the procedure followed and also on the operator-skill. The respirometric method with its opportunities for controlling biodegradation kinetics at any time has got advantages over traditional method of $\mathrm{BOD}_{5}$ and $\mathrm{COD}$ control, but still did not find much application in the laboratories associated with activated sludge plants. The probable reasons may be (1) expensive apparatus required for the application of respirometric method, (2) necessity of skilled and efficient operating personnel to interpret the acquired data and (3) too little data for comparison between respirometric and $\mathrm{BOD}_{5} / \mathrm{COD}$ method to convince someone about the advantages of the first on the later (Wenxiang et al. 2008; Rahman and Islam 2013).

In the past decades developing nations, specially Bangladesh, have made much progress in building their industrial base and are installing biological treatment units (DOE 2008; Sultana et al. 2013). For proper maintenance and successful operation of the plants, the associated laboratories are to be equipped with inexpensive facilities with low maintenance cost. The purpose of the present paper is to present a low-cost headspace gas respirometric device for measuring the oxygen and carbon dioxide concentration in the gas phase by manometric method. However, there are a number of commercial respirometers available in the market having different features and functional objectives. The present one may be considered as a cost-effective simplest form appropriate for the developing countries. A comparative description of the major features of some common batch respirometers is given in Table 1 . The performance of the respirometer has been tested with a standard glucoseglutamic acid (GGA) solution and the oxygen uptake data acquired from the biodegradation of the solution have been compared with those reported in the literature (Lee and Oswald 1954; Kessick 1976; Min et al. 2004). The theoretical ground of the measurement of oxygen depletion in the system has been discussed in a comprehensive manner and the calculation method has been summarized in a 
Table 1 Features of some commonly available batch respirometers

\begin{tabular}{lllll}
\hline References & $\begin{array}{l}\text { Basis of } \\
\text { operation }\end{array}$ & $\begin{array}{l}\text { Oxygen uptake measuring } \\
\text { device or method }\end{array}$ & Oxygen measuring phase & $\begin{array}{l}\text { Carbon dioxide } \\
\text { measuring option }\end{array}$ \\
\hline Grady et al. (1989) & Electrolytic & Oxygen replacement & Gas phase & - \\
Min et al. (2004) & Oxygen depletion & Fiber optic probe & Gas phase & - \\
Wenxiang et al. (2008) & Constant volume & Pressure change & Gas phase & - \\
Roppola (2009) & Manometric & Pressure change & Gas phase & - \\
Present work & Manometric & $\begin{array}{c}\text { Pressure and corresponding } \\
\text { volume change }\end{array}$ & $\begin{array}{c}\text { Gas phase (but calculation is based } \\
\text { on mass balance approach considering } \\
\text { both gas and liquid phase) }\end{array}$ & $\begin{array}{c}\text { Incorporated } \\
\text { (indirect estimation) }\end{array}$ \\
\hline
\end{tabular}

sequential order. Similarly, a concise calculation method for carbon dioxide generation is also presented in the paper. Efforts have been made to make a parallel between the traditional BOD concept and the oxygen consumption measured by the present respirometer. The method of determination of the Monod kinetic parameters based on the respirometric data has also been illustrated.

Although batch type closed respirometer has been widely used for treatment plant monitoring and controls for its simplicity and low-cost (Kim et al. 2001; Young and Cowan 2004; Tzoris and Hall 2006; Roppola 2009), due to its operation under oxygen limiting condition, it does not fully resemble the actual plant situation that usually exists in a suspended growth system in form of activated sludge. In that case, sensor-based open and/or continuous respirometry may provide good approximation which is not achievable through the present respirometer. However, proper scaling-up of the laboratory findings obtained from this respirometer may give satisfactory results for largescale treatment plant considering the kinetic trends, thermodynamics and hydrodynamics of fluid flow properly (Doble and Gummadi 2007).

\section{Description of the apparatus}

The present apparatus, named as 'BIOSUST multi-reactor respirometric system (BMRS), is a specially designed device based on the principle of headspace gas respiromerty with an option of measuring oxygen consumption and indirect estimation of carbon dioxide evolved during biodegradation process. The BMRS consists of six respirometric units (RU), each of which can operate independently. The oxygen consumption of the blank (consists of oxygen saturated dilution water along with seeding biomass) and the sample solutions with different dilutions can be studied simultaneously with the BMRS. Each RU comprises a constantly stirred batch reactor (CSBR) and an open tube manometric unit (Fig. 1). The reactor contains the sample solution stirred by a magnetic bar. The carbon dioxide

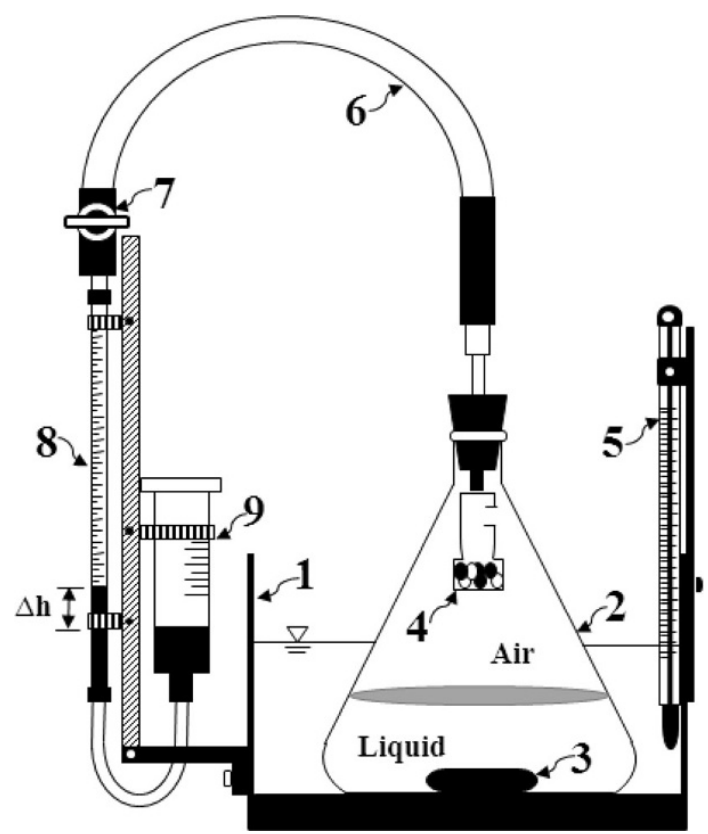

Fig. 1 Schematic diagram of a single respirometric unit (RU). 1 Water bath, 2 Constantly stirred batch reactor (CSBR), 3 Magnetic stirrer with stir-bar, $4 \mathrm{CO}_{2}$ absorber, 5 Thermometer, 6 Connecting tubing, 7 Control valve, 8 Measuring arm of the manometer and 9 Manometric liquid reservoir

scrubber is held in a hanging position. The gas space is connected with the manometer.

The CSBR of all the six respirometric units are placed in a common water bath, the temperature of which is maintained constant by a temperature control system. The body structure of the BMRS is organized in two sections (Fig. 2): (1) reaction section (situated on the rear side of the apparatus) containing the six reactors with all accessories and (2) measuring section (situated on the front side of the apparatus) containing the six manometers.

Reaction section

The body structure of this section represents a rectangular box of 18-gauge metal sheet with a polished white coating 


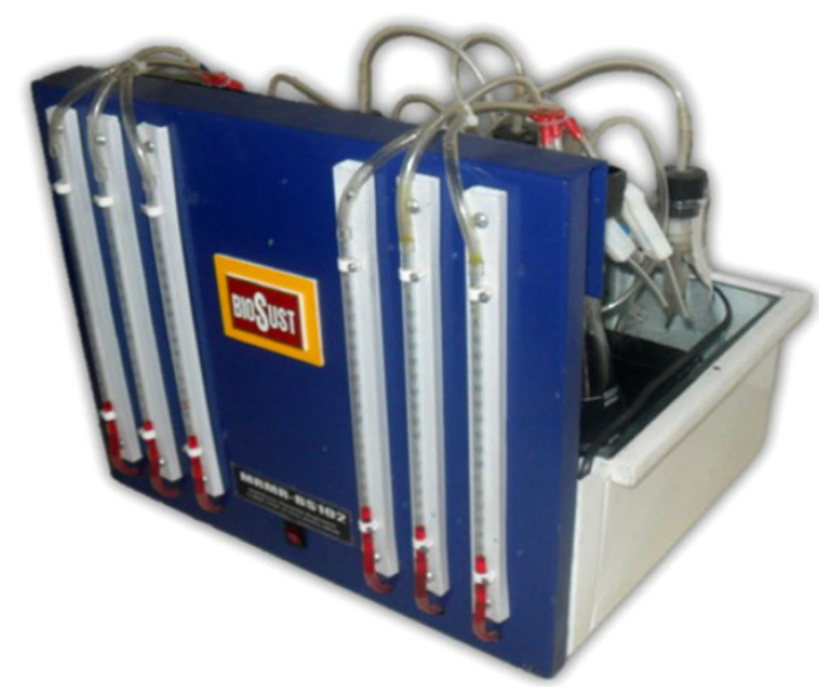

Fig. 2 The BMRS with six measuring units at the front side and the reaction section (partially shown) at the rear side

Table 2 Technical specification of the BMRS

\begin{tabular}{ll}
\hline Particulars & Description \\
\hline Manometer height & $25 \mathrm{~cm}(\mathrm{max})$ \\
Volume range & Approx. $1.5 \mathrm{ml}$ \\
Manometric liquid & Colored water solution \\
Temperature range & $(18-32 \pm 1){ }^{\circ} \mathrm{C}$ \\
Power supply & Input: $220 \mathrm{~V} \mathrm{AC}$, Output: $12 \mathrm{~V} \mathrm{DC}$ \\
Dimensions & $38 \mathrm{~cm} \times 33 \mathrm{~cm} \times 32 \mathrm{~cm}$ \\
Weight & Approx. $10 \mathrm{~kg}$ \\
\hline
\end{tabular}

surface. A 5-mm thick glass reservoir is placed within the unit with an automatic aquarium water heater of $50 \mathrm{~W}$ to serve as a temperature control unit for the CSBRs. The magnetic stirrer is made of six small cooling fans of 12 volt, and powerful magnets are placed at the bottom part of the unit. A power adaptor is connected to the back outer surface of the unit to supply DC current to the magnetic stirrers from a 220 AC source. Six conical flasks fitted with rubber stoppers and carbon dioxide scrubbers are used as experimental reaction cell. The reactors are made airtight so that no gases are leaked out from the system during the study.

\section{Measuring section}

This section constitutes a vertical plastic panel sheet holding the manometers in the vertical position. The two arms of the manometers are fixed at the two faces of the panel. The measuring arm of the well-type manometers is constructed with a $2-\mathrm{mm}$ laboratory pipette (located at the front side of the panel sheet) and is connected with a 5-ml plastic syringe as manometric liquid reservoir (located at the rear side of the panel sheet). Changes in the capillary height in the measuring arm do not make appreciable changes in the liquid-height of the reservoir arm. The open end of the measuring arm (volumetric pipette) is attached to the rubber stopper of the reaction flask through a 5-mm rubber tube. The oxygen uptake is read from the manometer arms at the front side. The technical specification of the BMRS is presented in Table 2.

\section{Theoretical ground of oxygen consumption measurement}

Assumptions for the treatment of the experimental data

The change in volume is monitored in the manometer tube as a function of time and the data is treated under the following assumptions:

1. The components of the gases in the headspace system follow ideal gas laws.

2. The partial pressure of the water vapor in the headspace is equal to its saturated vapor pressure, $p_{\mathrm{sw}}$, at the working temperature throughout the experimentation.

3. The oxygen consumption from the liquid phase is compensated by the transfer of oxygen from the liquid phase at such a rate that the oxygen concentration in the gas and the liquid phase are always in equilibrium and follow Henry law of gas solubility in liquid.

4. Carbon dioxide evolved in the process is totally absorbed by the scrubber.

5. No loss of gases are occurred during experimentation.

Formulae for the calculation of oxygen depletion

The changes in the amount of oxygen in the gas phase (correspondingly the partial pressure of oxygen) is calculated based on the volume and pressure variation data. Then the oxygen concentration in the liquid phase at every moment is calculated based on the assumption 3. Finally, the total amount of oxygen in gas and liquid phase altogether is calculated for every moment during the test course.

Gas phase

Referring to Fig. 1, the total number of moles of all the gases and vapors present at any time $t$ in the gas phase of the reactor is given by the following relation:

$n_{\mathrm{s}(\mathrm{g})}=n_{\mathrm{A}(\mathrm{g})}+n_{\mathrm{w}(\mathrm{g})}+n_{\mathrm{I}(\mathrm{g})}$

where $n$ stands for the number of moles and the subscripts $\mathrm{s}, \mathrm{A}, \mathrm{w}$ and I stand, respectively, for sum-total of the 
number of moles of all species, oxygen, water vapor and all other components of the gas mixture. The subscript $\mathrm{A}$ is used to denote 'Oxygen' instead of easily noticeable symbol $\mathrm{O}_{2}$ simply to avoid clumsiness of the notations. The subscript $\mathrm{g}$ indicates, gas phase'.

Initially (at $t=0$ ), the corresponding number of moles are given by the following relations in accordance with ideal and Dalton's gas law:

$$
\begin{aligned}
n_{\mathrm{s}(\mathrm{g})}^{0} & =P^{0} V_{(\mathrm{g})}^{0} /(R T), \quad n_{\mathrm{A}(\mathrm{g})}^{0}=y_{\mathrm{A}}^{0} n_{\mathrm{s}(\mathrm{g})}^{0}, n_{\mathrm{w}(\mathrm{g})}^{0} \\
& =a_{\mathrm{w}} n_{\mathrm{s}(\mathrm{g})}^{0} \quad \text { and } n_{\mathrm{I}(\mathrm{g})}^{0}=n_{\mathrm{s}(\mathrm{g})}^{0}\left(1-y_{\mathrm{A}}^{0}-a_{\mathrm{w}}\right)
\end{aligned}
$$

With $\quad a_{\mathrm{w}}=p_{\mathrm{sw}} / P^{0}$

where the superscript 0 indicates parameter at $t=0, V_{(\mathrm{g})}^{0}$ is the initial volume of the gas phase in the headspace $\left(\mathrm{m}^{3}\right)$, $R$ is the universal gas constant, $\mathrm{J} / \mathrm{mol} . K$ and $T$ is the working temperature, $K . P^{O}$ is the atmospheric pressure (assumed to be equal to $1.013 \times 10^{5} \mathrm{~Pa}$ ) and $y_{\mathrm{A}}^{0}$ is the initial mole composition of oxygen in the air and is assumed to be equal to 0.21 .

Assuming that the liquid level in the manometric liquid reservoir (see Fig. 1) does not change appreciably, at a given time $t$, the total number of moles in the gas phase, $n_{\mathrm{s}(\mathrm{g})}$, is given by the following relation:

$$
\begin{aligned}
n_{\mathrm{s}(\mathrm{g})} & =n_{\mathrm{s}(\mathrm{g})}^{0}\left(1-a_{\mathrm{h}} \Delta v\right)\left(1-a_{\mathrm{v}} \Delta v\right) \text { with } a_{\mathrm{h}} \\
& =\rho \mathrm{g} /\left(S_{\mathrm{m}} P^{0}\right) \text { and } a_{\mathrm{v}}=1 / V_{(\mathrm{g})}^{0}
\end{aligned}
$$

where $g$ is the acceleration due to gravity $\left(\mathrm{m} / \mathrm{s}^{2}\right), S_{\mathrm{m}}$ is the cross-sectional area of the manometer tube $\left(\mathrm{m}^{2}\right), \rho$ is the density of the manometer-liquid $\left(\mathrm{kg} / \mathrm{m}^{3}\right)$ and $\Delta v$ is the change in volume in the gas phase measured by the manometric tube $\left(\mathrm{m}^{3}\right)$.

Expanding Eq. (6) and neglecting the term containing square and higher order of $\Delta v$, the Eq. (6) is reduced to

$n_{\mathrm{s}(\mathrm{g})} \approx n_{\mathrm{s}(\mathrm{g})}^{0}\left[1-\left(a_{\mathrm{h}}+a_{\mathrm{v}}\right) \Delta v\right]$

The number of moles of water vapor, inert gases and oxygen (A) in the gas phase at any time $t$ are given by the following relations:

$n_{\mathrm{w}(\mathrm{g})}=n_{\mathrm{w}(\mathrm{g})}^{0}\left(1-a_{\mathrm{v}} \Delta v\right)=a_{\mathrm{w}} n_{\mathrm{s}(\mathrm{g})}^{0}\left(1-a_{\mathrm{v}} \Delta v\right)$ and

$n_{\mathrm{I}(\mathrm{g})}=n_{\mathrm{I}(\mathrm{g})}^{0}$

and

$$
\begin{aligned}
n_{\mathrm{A}(\mathrm{g})} & =n_{\mathrm{s}(\mathrm{g})}-n_{\mathrm{w}(\mathrm{g})}-n_{\mathrm{I}(\mathrm{g})}=n_{\mathrm{s}(\mathrm{g})}^{0}\left(y_{\mathrm{A}}^{0}-a_{\mathrm{n}} \Delta v\right) \text { with } a_{\mathrm{n}} \\
& =a_{\mathrm{h}}+a_{\mathrm{v}}-a_{\mathrm{w}} a_{\mathrm{v}}
\end{aligned}
$$

The number of moles, $\Delta n_{\mathrm{A}(\mathrm{g})}$, (and the corresponding mass $\left.\Delta m_{\mathrm{A}(\mathrm{g})}\right)$ of oxygen depleted in the gas phase are given by the following relations:

$$
\begin{aligned}
\Delta n_{\mathrm{A}(\mathrm{g})} & =n_{\mathrm{s}(\mathrm{g})}^{0} a_{\mathrm{n}} \Delta v \Rightarrow \Delta m_{\mathrm{A}(\mathrm{g})}=a_{\mathrm{m}(\mathrm{g})} \Delta v \quad \text { with } \\
a_{\mathrm{m}(\mathrm{g})} & =n_{\mathrm{s}(\mathrm{g})}^{0} a_{\mathrm{n}} M_{\mathrm{A}}
\end{aligned}
$$

where $M_{\mathrm{A}}$ is the molecular mass of oxygen $\left(=32 \times 10^{-3}\right.$ $\mathrm{kg} / \mathrm{mol})$.

\section{Liquid phase}

The concentration of oxygen, $C_{\mathrm{A}(\mathrm{L})}\left(\mathrm{kg} / \mathrm{m}^{3}\right)$ in the aqueous phase (denoted by the subscript L) initially and at any time $t$ are related to its partial pressure by Henry law as follows:

$C_{\mathrm{A}(\mathrm{L})}^{\mathrm{o}}=P_{\mathrm{A}}^{0} / H$ and $C_{\mathrm{A}}=P_{\mathrm{A}} / H$

where $H\left(\mathrm{~Pa} . \mathrm{m}^{3} / \mathrm{kg}\right)$ is the Henry constant at the temperature $T$, and $P_{\mathrm{A}}$ is the partial pressure of oxygen.

The partial pressure of oxygen (A) initially and at any time $t$ are given by the following relations:

$$
\begin{aligned}
P_{\mathrm{A}}^{0} & =y_{\mathrm{A}}^{0} P^{0} \text { and } P_{\mathrm{A}(\mathrm{g})}=\frac{n_{\mathrm{A}(\mathrm{g})} R T}{V_{(\mathrm{g})}^{0}-\Delta v} \\
& =P^{0}\left(y_{\mathrm{A}}^{0}-a_{\mathrm{n}} \Delta v\right)\left(1-a_{\mathrm{v}} \Delta v\right)^{-1}
\end{aligned}
$$

Expanding the last term of the Eq. 15 and neglecting square and higher terms of $\Delta v$, we obtain

$$
\begin{aligned}
P_{\mathrm{A}(\mathrm{g})} & =P^{0}\left(y_{\mathrm{A}}^{0}-a_{\mathrm{n}} \Delta v\right)\left(1-a_{\mathrm{v}} \Delta v\right)^{-1} \\
& \approx P^{0}\left(y_{\mathrm{A}}^{0}-a_{\mathrm{p}} \Delta v\right) \quad \text { with } a_{\mathrm{p}}=a_{\mathrm{n}}-y_{\mathrm{A}}^{0} a_{\mathrm{v}}
\end{aligned}
$$

The change in the concentration of oxygen in the liquid phase, $\Delta C_{\mathrm{A}(\mathrm{L})}\left(\mathrm{kg} / \mathrm{m}^{3}\right)$ is expressed as follows:

$\Delta C_{\mathrm{A}(\mathrm{L})}=C_{\mathrm{A}(\mathrm{L})}^{0}-C_{\mathrm{A}(\mathrm{L})}=\Delta P_{\mathrm{A}} / H=\left(P^{0} a_{\mathrm{p}} / H\right) \Delta v$

The oxygen-depletion in the liquid phase (expressed in $\mathrm{kg}$ ) is calculated by the following relation:

$$
\begin{aligned}
\Delta m_{\mathrm{A}(\mathrm{L})} & =\Delta C_{\mathrm{A}(\mathrm{L})} \times V_{\mathrm{L}}=a_{\mathrm{m}(\mathrm{L})} \Delta v \text { with } a_{\mathrm{m}(\mathrm{L})} \\
& =P^{0} a_{\mathrm{p}} V_{\mathrm{L}} / H
\end{aligned}
$$

Finally, the oxygen-depletion (in $\mathrm{kg}$ ) from the whole gas-liquid system, i.e. oxygen demand (OD) is given by the following relation:

$$
\begin{aligned}
\mathrm{OD}=\Delta m_{\mathrm{A}(\mathrm{g}, \mathrm{L})} & =a_{\mathrm{m}(\mathrm{g}, \mathrm{L})} \Delta v \\
\text { with } \quad a_{\mathrm{m}(\mathrm{g}, \mathrm{L})} & =a_{\mathrm{m}(\mathrm{g})}+a_{\mathrm{m}(\mathrm{L})}
\end{aligned}
$$

Summary of the data treatment procedure in working form

The first task is to calculate the coefficient for the transformation of the volume change $\Delta v$ data to the mass change, $\Delta m_{\mathrm{A}}$ data for the oxygen in the system. For the purpose, the following calculations (Steps 1 through 9) are to be done sequentially. This is a preparatory step and can be done before conducting the experiment.

Step 1: Record $V^{0}{ }_{(\mathrm{g})}, V_{\mathrm{L}}, S_{\mathrm{m}}$ and the temperature $T$

Step 2: Assume $P^{O}=1.013 \times 10^{5} \mathrm{~Pa}$ and $y_{\mathrm{A}}^{0}=0.21$. 
Step 3: Find $p_{\mathrm{sw}}(\mathrm{Pa})$ and Henry constant $H$ at the temperature $T$ from some reference book

Step 4: Calculate $n_{\mathrm{s}(\mathrm{g})}^{0}$ (Eq. 2), $a_{\mathrm{w}}$ (Eq. 5a), and $a_{\mathrm{h}}$ and $a_{\mathrm{v}}$ (Eq. 6)

Step 5: Calculate $a_{\mathrm{n}}$ (Eq. 9)

Step 6: Calculate $a_{\mathrm{m}(\mathrm{g})}$ (Eq. 11)

Step 7: Calculate $a_{\mathrm{p}}$ (Eq. 16)

Step 8: Calculate $a_{\mathrm{m}(\mathrm{L})}$ (Eq. 18)

Step 9: Calculate $a_{\mathrm{m}(\mathrm{g}, \mathrm{L})}$ (Eq. 19)

Knowing the value of $a_{\mathrm{m}(\mathrm{g}, \mathrm{L})}$, the $\Delta v$ vs. $t$ data can readily be transformed into OD vs. $t$ data.

\section{Indirect estimation of carbon dioxide from manometric reading}

This particular headspace gas respirometer is designed to measure the amount of oxygen consumed by the biomass under the assumption that the evolved carbon dioxide will be completely absorbed by the caustic scrubber placed in the scrubber tube within the reactor. Although these measurements usually over-simplify the actual situation as they do not consider the effect of liquid-phase $\mathrm{pH}$ and oxygen and carbon dioxide transfer limitations. However, there is an option of indirect estimation of carbon dioxide (approximately) generated in the biodegradation process. To perform this type of analysis, the apparatus needs to orient in a particular fashion where three types of wastewater samples with two replicas from each group are to be placed in the six CSBRs of the respirometer. One sample from each group is placed in a reactor having carbon dioxide scrubbing system while the other is placed in the second reactor without the scrubber. Then the new positions of the manometer fluid after a certain interval are recorded to find out the amount of carbon dioxide generated during the biodegradation phase.

Referring to Fig. 3, let the net volume changed in time $t$ considering full carbon dioxide absorption in the reactor by the scrubber is $\Delta V_{1}$ (measured by the manometer tube) and the net volume changed in the same duration $t$ considering no absorption of carbon dioxide is $\Delta V_{2}$ (it may be positive or negative).

Since in both cases, same amount of carbon dioxide get dissolved in the liquid phase, considering the volume and pressure variation only in the gas phase the amount of carbon dioxide evolved (CE) in the system can be approximated from the following relation:

$\mathrm{CE}=\frac{P^{0} M_{\mathrm{CO}_{2}}}{R T}\left(1+\frac{\rho g V_{(\mathrm{g})}^{0}}{S_{\mathrm{m}} P^{0}}\right)\left(\Delta V_{1} \pm \Delta V_{2}\right)$

where, $M_{\mathrm{CO}_{2}}$ is molecular mass of the carbon dioxide $(\mathrm{kg} / \mathrm{mol})$.

From the last two equations, i.e. 19 and 20, an important dimensionless ratio could be calculated which is called respiratory quotient (RQ) and can be expressed as

$\mathrm{RQ}=\frac{\mathrm{CE}}{\mathrm{OD}}=\frac{\mathrm{CO}_{2} \text { Evolved }}{\mathrm{O}_{2} \text { Demand (i.e. consumed) }}$

\section{Demonstration of the performance of the device}

The performance of a RU of BMRS is tested by monitoring the oxygen uptake during the biodegradation of a glucoseglutamic acid standard solution. The data have been compared with those available in literature (Lee and Oswald 1954; Kessick 1976; Min et al. 2004). Also the biodegradation of the wastewater from an industrial plant has been monitored through oxygen uptake measurement in the five RUs of BMRS at different dilutions and the method of the determination of the bio-kinetic coefficients has been illustrated with the acquired data. Finally, the respiratory quotients of the effluent samples collected from three different effluent treatment plants (ETP) have also been determined.

Check with standard glucose-glutamic acid (GGA) solution

The oxidative potential of a given amount of seed inoculum (biomass agent) as well as the reliability of a BOD measuring instrument are checked periodically by monitoring the oxygen uptake data of some pure organic compounds for which BOD is known or determinable. One of the most commonly used such compounds is a mixture of glucose $\left(\mathrm{C}_{6} \mathrm{H}_{12} \mathrm{O}_{6}\right)$ and glutamic acid $\left(\mathrm{C}_{5} \mathrm{H}_{9} \mathrm{NO}_{4}\right)$, and a mixture of $150 \mathrm{mg} / \mathrm{L}$ of each is recommended in $1 \mathrm{~L}$ aqueous solution (APHA 2005). Pure glucose has an exceptionally high oxidation rate with relatively simple seeds. When used with glutamic acid, the oxidation rate is stabilized and is similar to that of most municipal wastewater (Ramalho 1977). Stoichiometrically, ThOD for $150 \mathrm{mg}$ of Glucose is $160 \mathrm{mg}$ and that for the $150 \mathrm{mg}$ of Glutamic acid is $212.2 \mathrm{mg}$. Therefore, the theoretical chemical oxygen demand for the prepared GGA solution is $372.2 \mathrm{mg} / \mathrm{L}$. For biodegradation studies, a small volume, $v_{\mathrm{s}}$ (ml), of the GGA solution is diluted to a total test volume $V_{\text {test }}$ (standard volume $=300 \mathrm{ml}$ ) of oxygen-saturated aqueous solution containing the seed and the oxygen depletion is monitored for the diluted solution.

The oxygen consumption data from a biodegradation experiment are conventionally presented by a concept called oxygen uptake $(\mathrm{OU})(\mathrm{mg} / \mathrm{L})$ which is related to the oxygen demand (OD) as follows:

$\mathrm{OU}=\frac{\mathrm{OD}}{v_{\mathrm{s}}} \times 10^{9}=\frac{\mathrm{OD} \times \mathrm{DF}}{V_{\text {test }}} \times 10^{9} \quad$ with

Dilution factor $(\mathrm{DF})=V_{\text {test }} / v_{\mathrm{s}}$

For studying the biodegradation of the GGA solution in the present work, a special type of commercial microbial 
Fig. 3 Schematic diagram of the respirometer setup for $\mathrm{CO}_{2}$ measurement: $R_{1}$ Reactor with $\mathrm{CO}_{2}$ absorber, $R_{2}$ Reactor without $\mathrm{CO}_{2}$ absorber, $M_{1}$ Manometer linked with $R_{1}$ reactor showing net volume change as $\Delta V_{1}$ and $M_{2}$ Manometer linked with $R_{2}$ reactor showing the net volume change as $\Delta V_{2}$ (similar arrangement will be made for the remaining reactors)

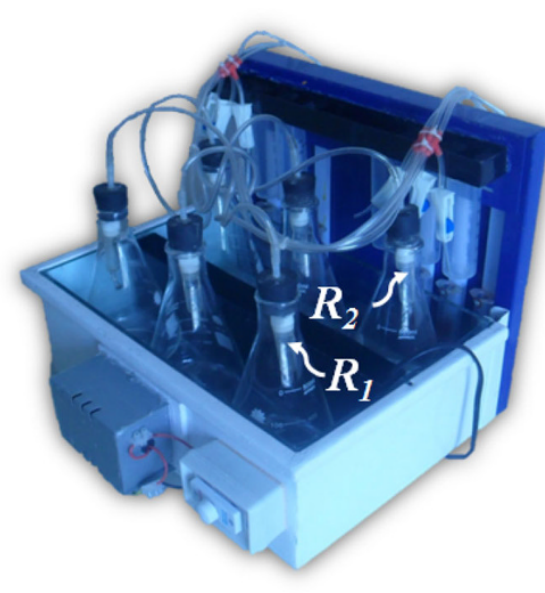

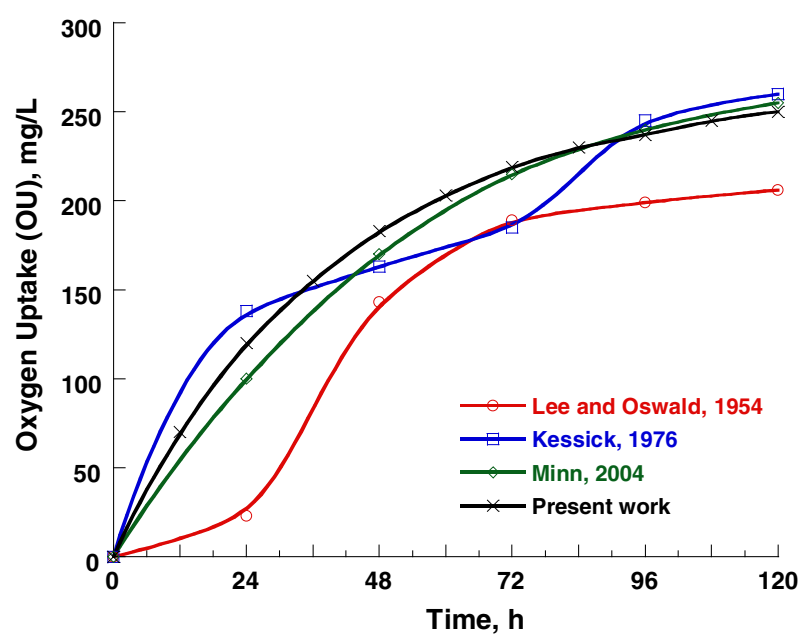

Fig. 4 Oxygen Uptake (OU) profile for GGA solution

blend named as, Probios plus', product of Jayson Agrovet, Bangladesh, was used as the seed. The seed solution was prepared by rehydrating $10 \mathrm{~g}$ dry probios in $100 \mathrm{ml}$ distilled water with aeration for $1 \mathrm{~h}$ followed by 10-min-long settling for the separation of bran material from the seeded supernatant. The solution in the RU contained $5 \mathrm{ml}$ of GGA standard solution, $10 \mathrm{ml}$ probios and $285 \mathrm{ml}$ oxygen saturated distilled water. The oxygen uptake profile of the GGA solution is presented in Fig. 4. Similar data available in the literature (Lee and Oswald 1954; Kessick 1976; Min et al. 2004) have also been presented in the Figure for comparison.

The biodegradation rate is seed-specific, which results in different oxygen consumption rate for the same effluent (Ramalho 1977; Rahman et al. 2013). But still three of the curves (excluding that of Lee and Oswald 1954) have shown satisfactorily similar oxygen uptake profile for a biodegradation period of $120 \mathrm{~h}$, with the oxygen uptake value lying in the range of $250-260 \mathrm{mg} / \mathrm{L}$. Therefore, it can be concluded that the BMRS can successfully and reliably be used to monitor biodegradation process and to determine the biokinetic coefficients in wastewater treatment processes.

Parallel Respirometric and BOD test using dilution series

To make a comparative analysis, the respirometric and conventional BOD tests were also performed with the same dilution series. The object of biodegradation study was chosen arbitrarily, and it represents a wastewater sample collected from the outlet enriched with food processing industrial discharge. The characteristic features of the test sample are presented in the Table 3 . The sample was rich in microorganism and no seed was used from outside. For respirometric study, five reactors were run at a time with different dilutions of the sample while sixth reactor was used to monitor the manometric observation corresponds to the thermobarometric change during the experiment. For BOD tests, five $300 \mathrm{~mL}$ BOD bottles were charged with the wastewater with the same dilutions. Both the tests were conducted at $30^{\circ} \mathrm{C}$ for a period of $120 \mathrm{~h}$. The oxygen uptake profile of the demonstration test is presented in Fig. 5.

As seen from the Fig. 5, the oxygen uptake increases with the progress of the biodegradation process, but the rate gradually decreases showing a trend to become zero as the uptake approaches some limiting value. The initial uptake rate is the highest for the highest dilution. Such saturate type of curve could easily be described by an empirical equation of the type (Metcalf and Eddy 2005):

$\mathrm{BOD}_{\mathrm{t}}=\mathrm{BOD}_{\infty}\left(1-e^{-k t}\right)$

where BOD is the biochemical oxygen demand (equivalent to oxygen uptake, $\mathrm{OU}$ ) up to time $t, \mathrm{BOD}_{\infty}$ (equivalent to the ultimate oxygen uptake, $\mathrm{OU}_{\infty}$ ) is the amount of oxygen consumed for $t \rightarrow \infty$ (the whole biodegradable mass is 
Table 3 Characteristics of the test sample for parallel respirometric and BOD test

\begin{tabular}{lllllllll}
\hline Wastewater type & Physical appearance & $\mathrm{pH}$ & $\mathrm{TS}(\mathrm{mg} / \mathrm{L})$ & $\mathrm{DS}(\mathrm{mg} / \mathrm{L})$ & $\mathrm{SS}(\mathrm{mg} / \mathrm{L})$ & $\mathrm{COD}(\mathrm{mg} / \mathrm{L})$ & $\mathrm{NO}_{3}(\mathrm{mg} / \mathrm{L})$ & $\mathrm{PO} \mathrm{C}_{4}(\mathrm{mg} / \mathrm{L})$ \\
\hline Food processing industry & Milky white, foul odor & 8.2 & 780 & 370 & 410 & 630 & 30 & 29.5 \\
\hline
\end{tabular}

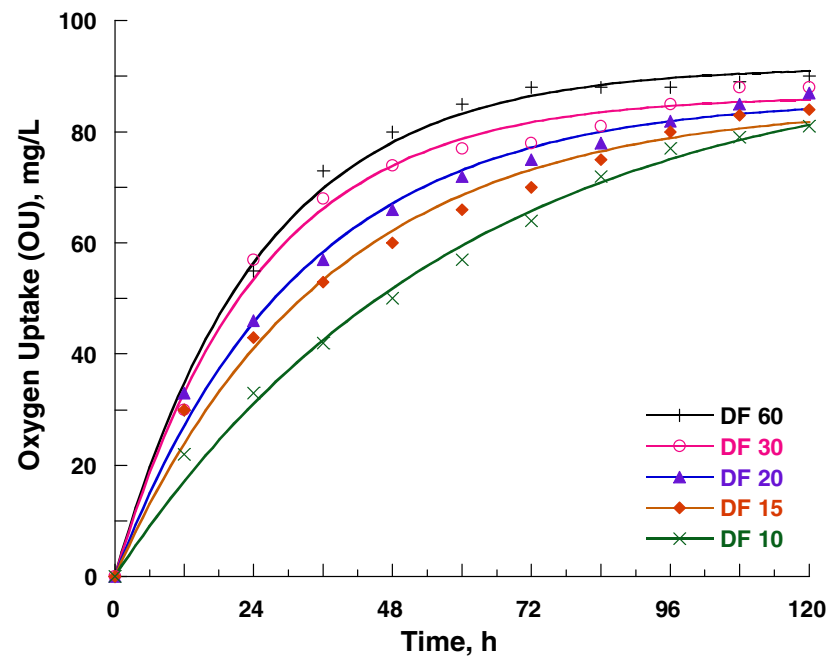

Fig. 5 Oxygen uptake profiles of a real wastewater sample run simultaneously with five different dilutions

removed), and $k$ is the rate constant of a pseudo first-order biodegradation process. The OU-data of simultaneously operating RU units have been fitted to the Eq. (23), and the fitted parameters have been estimated. These parameters together with the oxygen uptake value at $t=120 \mathrm{~h}, \mathrm{OU}_{120}$ (read from the averaged curves) are presented in Table 4 along with the measured $\mathrm{BOD}_{5}$ for comparison.

The $\mathrm{OU}_{120}$-values obtained from different dilutions are uniformly distributed around the averaged value $(86 \pm 4 \mathrm{mg} / \mathrm{L})$, whereas the equivalent $\mathrm{BOD}_{5}$-values are much scattered around its averaged value $(109 \pm 33 \mathrm{mg} /$ $\mathrm{L})$. The $\mathrm{BOD}_{5}$-values are much affected by the dilution factors (Young and Cowan 2004). The average $\mathrm{BOD}_{5}$-range as found in this work encompasses the average $\mathrm{OU}_{120^{-}}$ range. Thus the average $\mathrm{OU}_{120}$-value may be accepted as the $\mathrm{BOD}_{5}$-value of the wastewater with some reservation as the average $\mathrm{OU}_{120}$-value lies near the lower limit of the $\mathrm{BOD}_{5}$-range. This might be an effect from the assumption in the respirometric analysis that the concentration of the oxygen in the liquid and gas phases are always in equilibrium (Kuyen and Yuebo 1996). The resistance to the masstransfer of the gaseous to the liquid phase might be high enough that the oxygen concentration in the liquid is maintained at a level lower than its equilibrium value. In BOD test, the oxygen concentration is measured in the liquid phase where the biodegradation process actually takes place. For more precise respirometric analysis, the oxygen concentration in the aqueous phase should also be monitored simultaneously with the oxygen concentration in the gaseous phase. In spite of the bit lower $\mathrm{OU}_{120^{-}}$values as compared to the corresponding $B O D_{5}$-values, the advantage of the respirometric method is that it provides information about the biodegradation kinetics as well as $\mathrm{OU}_{\infty}$-values. This parallel study has categorically demonstrated that the RU units of the present device along with the developed procedure of OD-calculation can successfully replace the traditional BOD tests and provides more information about the biodegradation process than the BOD does.

Calculation of respiratory quotients of the effluent samples collected from different ETPs

Measurement of the rate of oxygen utilization and carbon dioxide production by activated sludge-sewage mixtures has become prominent in recent years as a criterion of sludge activity and other characteristics of the activated sludge methods of sewage treatment (Sawyer and Nichols 1939; Genc and Yonsel 2007). The respiratory quotient (RQ), in this regard, plays an important role in aerobic respirometric investigations as its value depends on the substrate type, microorganisms present and on the environmental conditions too (Dilly 2001; ASAP 2012). This value can indicate the presence of different metabolic pathways, e.g. nitrification, denitrification, and anaerobic metabolic routes (Dilly 2003). Moreover, RQ can be used as a control parameter to supply a process with an optimum concentration of oxygen (Zeng et al. 1994; Franzén et al. 1996) or to control the feed rate (Aiba and Furuse 1990). Therefore, handling and operation procedures and appropriate treatment strategy could be selected considering the RQ values of the wastewater and activated sludge samples. In this case three wastewater samples collected from three different effluent treatment plants were selected to use and a high-rate batch test protocol was followed. The characteristic features of the test sample and experimental outcome are presented in the Table 5. All the tests were conducted at $30{ }^{\circ} \mathrm{C}$ for a period of $6 \mathrm{~h}$ only.

As like previous discussion, here also a clear difference was observed between conventional BOD and respirometric oxygen consumption. However, in this case, incubation time extends for a short duration $(6 \mathrm{~h})$ under a high rate test protocol against strong biomass agents collected from a reaction tank of an activated sludge plant. This type of experiment yields extant kinetics of a test sample 
Table 4 Different parameters obtained from respirometric and conventional BOD methods

\begin{tabular}{|c|c|c|c|c|c|c|c|}
\hline \multirow{2}{*}{$\begin{array}{l}\text { Test Method } \rightarrow \\
\text { Dilution factor DF } \downarrow\end{array}$} & \multicolumn{5}{|c|}{ Respirometric Method } & \multicolumn{2}{|c|}{ Conventional BOD Method } \\
\hline & $\begin{array}{l}\mathrm{OU}_{120} \\
(\mathrm{mg} / \mathrm{L})\end{array}$ & $\begin{array}{l}\text { Average } \mathrm{OU}_{120} \\
(\mathrm{mg} / \mathrm{L})\end{array}$ & $\begin{array}{l}\mathrm{OU}_{\infty} \\
(\mathrm{mg} / \mathrm{L})\end{array}$ & $\begin{array}{l}\text { Average } \mathrm{OU}_{\infty} \\
(\mathrm{mg} / \mathrm{L})\end{array}$ & $k\left(\mathrm{~h}^{-1}\right)$ & $\begin{array}{l}\mathrm{BOD}_{5} \\
(\mathrm{mg} / \mathrm{L})\end{array}$ & $\begin{array}{l}\text { Average } \mathrm{BOD}_{5} \\
(\mathrm{mg} / \mathrm{L})\end{array}$ \\
\hline 60 & 90 & $86 \pm 4$ & 92 & $90 \pm 3$ & 0.041 & 156 & $109 \pm 33$ \\
\hline 30 & 88 & & 90 & & 0.040 & 129 & \\
\hline 20 & 87 & & 88 & & 0.032 & 96 & \\
\hline 15 & 84 & & 86 & & 0.027 & 90 & \\
\hline 10 & 81 & & 94 & & 0.017 & 74 & \\
\hline
\end{tabular}

Table 5 Characteristic features of the test samples collected from ETPs and their respirometric and conventional BOD results

\begin{tabular}{|c|c|c|c|c|c|}
\hline Test sample & $\mathrm{pH}$ & $\begin{array}{l}\text { COD } \\
(\mathrm{mg} / \mathrm{L})\end{array}$ & $\begin{array}{l}\mathrm{BOD}_{6 \mathrm{~h}} \\
(\mathrm{mg} / \mathrm{L})\end{array}$ & $\begin{array}{l}\mathrm{OU}_{6} \mathrm{~h} \\
(\mathrm{mg} / \mathrm{L})\end{array}$ & RQ \\
\hline Municipal effluent & 7.2 & 455 & 81 & 75 & 0.55 \\
\hline $\begin{array}{l}\text { Confectionery } \\
\text { effluent }\end{array}$ & 8.2 & 630 & 53 & 45 & 1.19 \\
\hline $\begin{array}{l}\text { Recycled paper mill } \\
\text { effluent }\end{array}$ & 5.3 & 780 & 61 & 54 & 0.84 \\
\hline
\end{tabular}

(Young and Cowan 2004). Sample collected from municipal wastewater treatment plant showing a RQ value of 0.55 indicates the presence of a diverse type of mix substrates while the confectionery effluent having a RQ value of 1.19 indicates the presence of higher amount of carbohydrate groups. Since the sources of the samples and the experimental conditions are different from those found in the literature, it is quite difficult to make a significant comparison between these values. However, the findings of the current study are consistent with those of Kovács et al. (2007) who found 1.2 of RQ during biodegradation tests using glucose and sewage sludge as feed which closely resembles the confectionery effluent that contains high amount of carbohydrate ingredients. The RQ value determined by Sawyer and Nichols (1939) falls between the limits of 0.51 and 1.18 for activated sludge-sewage mixture which is quite similar to municipal effluent in nature and the current finding (i.e. 0.55) also lies within the range. On the other hand, a RQ value of 0.84 was found for the effluent collected from the recycled paper industry. However, the value found for paper sludge was 0.92 by Atkinson et al. (1997) which is quite close to the present results.

From what has been said above, it will be clear that the determination of the RQ is important as an indicator of the type of substrates involved and the nature of some of the various phases of the respiration process in the sample. However, the interpretation of result from this measurement should be done with some reservations. In many cases, more than one substrate may be utilized at the same time or more than one chain of reaction may be involved in the degradation of the substrate. Since respiration may signify the simultaneous utilization of a mixture of several different substrates, the calculated RQ represents an overall or average gaseous exchange for the combustion of the entire complex of materials. However, ETP personnel could make a rough idea about the type of influent wastewater and subsequent follow-up steps could be formulated and maintained measuring the extant kinetics of the raw sample through continuous monitoring of oxygen uptake and respiratory quotient of the representing test samples collected from the plant.

\section{Analysis of growth kinetics of wastewater}

Design, monitoring and performance-evaluation of a biological treatment plant exclusively depend on the microbial growth parameters of the wastewater. Due to the lack of proper growth kinetics data, most of the biological reactors, in most cases, are found to have poor design dimension and uneven treatment results (Kovar and Egli 1998; Metcalf and Eddy 2005). To overcome this situation oxygen uptake measurement can be a good alternative for the designer, investor and plant operators. Unlike BOD test, the respirometric method provides adequate data for such analysis. In the following sections, model-based discussion has been made on the relationship between the oxygen uptake rate and the microbial growth kinetics, and also the procedure of the determination of the biokinetic coefficients from the oxygen uptake data obtained from BMRS has been illustrated. Thus the data already presented in Fig. 5 undergo further treatment to determine biokinetic coefficients.

Relation between the microbial growth kinetics and oxygen uptake rate

Biological growth kinetics can be expressed by the wellknown Monod model. The relationship between the growth rate and limited substrate concentration in a batch culture 
process can be expressed by the following equation (Metcalf and Eddy 2005):

$\frac{\mathrm{d} X}{\mathrm{~d} t}=\left(\mu_{\mathrm{m}} \frac{S}{K_{\mathrm{s}}+S}-k_{\mathrm{d}}\right) X$

where $X(\mathrm{mg} / \mathrm{L})$ is the biomass concentration at any time $t$, $S(\mathrm{mg} / \mathrm{L})$ is the substrate concentration, $\mu_{\mathrm{m}}\left(\mathrm{h}^{-1}\right)$ is the maximum specific growth rate, $K_{\mathrm{s}}(\mathrm{mg} / \mathrm{L})$ is the half saturation constant and $k_{\mathrm{d}}\left(\mathrm{h}^{-1}\right)$ is the decay coefficient. Expressing the substrate concentration $S$ in terms of COD (Yoong et al. 2000), the Eq. (24) is reduced to

$\frac{\mathrm{d} X}{\mathrm{~d} t}=\left(\mu_{\mathrm{m}} \frac{\mathrm{COD}}{K_{\mathrm{s}}+\mathrm{COD}}-k_{\mathrm{d}}\right) X$

To use respirometric data for the analysis of growth kinetics, the oxygen uptake is to be related to $X$ and COD. For the simplicity of the analysis, the oxygen uptake data are related to the biomass growth and the COD consumption by the following linear relationship (Rozich and Gaudy 1992)

$X=X_{0}+\beta \mathrm{OU} \quad$ with $\quad \beta=\frac{Y}{1-Y O_{x}}$

where $Y$ is the biomass yield coefficient and $O_{\mathrm{x}}$ is the oxidative potential of the biomass. $Y$ can be determined from individual batch kinetic tests for $\Delta X$ vs. $\Delta C O D$ data using a laboratory fermentor. A rough estimation of $Y$ by Eq. (27), however, seems satisfactory for respirometric analysis of biodegradation assuming an average value of $O_{\mathrm{x}}$ in the range of 1.42-1.48 (Contreras et al. 2002; Chiil et al. 2008).

$Y=(1-\Delta \mathrm{OU} / \Delta \mathrm{COD}) / O_{x}$

In that case, the COD is to be measured at two points (initially and immediately after the completion of the experiment) and $Y$ can be estimated from Eq. (27) (Choung et al. 1999). To estimate the biomass concentration $X$ at any time $t$, the initial biomass concentration $X_{0}$ should be measured separately and then OU vs. $t$ data from respirometric measurements can be transformed into $X$ vs. $t$ data by Eq. (26).

Illustration of the method for the determination of biokinetic coefficients

As discussed in the previous section, to determine the biokinetic coefficients $\mu_{\mathrm{m}}, K_{\mathrm{s}}$ and $k_{\mathrm{d}}$, the value of $Y$ and $O_{x}$ have to be determined first. For the purpose, the COD and the VSS were measured for the undiluted sample and the corresponding initial COD and the initial $X$ in each RU were calculated based on the dilution factor. The final COD was measured for a single sample with $\mathrm{DF}=10$ after the experiment was over $(t=120 \mathrm{~h})$, and the value of $Y$ was calculated for this sample from Eq. (27) assuming that
$O_{x}=1.45$. The value of $Y$ in this demonstration experiment was found to be 0.61 . Such set of value for $O_{x}=1.45$ and $Y=0.61$ are satisfactorily in the same order as those found by previous authors (Park et al. 1997; Choung et al. 1999; Chiil et al. 2008). With known (or assumed) value of $Y, O_{x}$ and $X_{0}$ for each dilution, the OU-data are quite adequate to determine the biokinetic coefficients $\mu_{\mathrm{m}}, K_{\mathrm{s}}$ and $k_{\mathrm{d}}$.

For the determination of the biokinetic coefficients, the Eq. (25) is rewritten as Eq. (28):

$\frac{\mathrm{d} \ln X}{\mathrm{~d} t}=\mu_{\mathrm{m}} \frac{\mathrm{COD}}{K_{\mathrm{s}}+\mathrm{COD}}-k_{\mathrm{d}}$

The experimentally obtained OU vs. $t$ data are transformed into $X$ vs. $t$ through the Eq. (26). Then $\ln X$ vs. $t$ plot can be drawn. The COD being a decreasing function of time in any RU, the slope of the curve described by the right-hand side term of the Eq. (28) is also decreasing. The change in COD value is not monitored and hence the slope at arbitrary point cannot be used for analysis. At $t=0$, however, the COD is known and thus the initial slope will be useful for further analysis. Thus,

$\left(\frac{\mathrm{d} \ln X}{\mathrm{~d} t}\right)_{t \rightarrow 0}=m_{0}=\mu_{\mathrm{m}} \frac{\mathrm{COD}_{0}}{K_{\mathrm{s}}+\mathrm{COD}_{0}}-k_{\mathrm{d}}$

where $m_{0}$ is the initial slope of the $\ln X$ vs. $t$ plot. Now the $m_{0}$ vs. $\mathrm{COD}_{0}$ data can be plotted and fitted to the Eq. (29) by a program like KaleidaGraph to give the value of the biokinetic coefficients $\mu_{\mathrm{m}}, K_{\mathrm{s}}$ and $k_{\mathrm{d}}$. Due to the specific nature of the relation in Eq. (29), few $m_{0}$ vs. $\mathrm{COD}_{0}$ data (only fine points in our case) might show large ranges of the three biokinetic coefficients satisfying the Eq. (29). Better result is expected if the effect of $k_{\mathrm{d}}$ in the process is ignored and thus, the Eq. (29) is approximated as

$m_{0} \approx \mu_{\mathrm{m}} \frac{\mathrm{COD}_{0}}{K_{\mathrm{s}}+\mathrm{COD}_{0}} \Rightarrow \frac{1}{m_{0}}=\frac{K_{\mathrm{s}}}{\mu_{\mathrm{m}}} \times \frac{1}{\mathrm{COD}_{0}}+\frac{1}{\mu_{\mathrm{m}}}$

Thus, a $1 / m_{0}$ vs. $1 / \mathrm{COD}_{0}$ plot will be a straight line and from the slope and the intercept of the straight line, the fitted value of $\mu_{\mathrm{m}}$ and $K_{\mathrm{s}}$ can be determined.

The data from the Fig. 5 have been treated by Eq. (26) and are presented in Fig. 6 as a $\ln X$ vs. $t$ plot. As predicted by Eq. (29), the slope of the curves gradually decreases. The slope, $m_{0}$, of the curves at $t \rightarrow 0$ were estimated for further treatment. Finally, $1 / m_{0}$ vs. $1 / \mathrm{COD}_{0}$ plot is presented in Fig. 7 and the data are fitted to the straight line described by the Eq. (30). The fitted value of $\mu_{\mathrm{m}}$ and $K_{\mathrm{s}}$ are found to be $0.048 \mathrm{~h}^{-1}$ and $96 \mathrm{mg} / \mathrm{L}$.

This illustration shows the further opportunity of using the data acquired by the present device. The OU-data can be routinely treated to evaluate the state of the activated sludge in an operating plant and the operating parameters can be regulated for better performances. Actual biokinetic coefficients can be determined on the spot and be used (instead of 


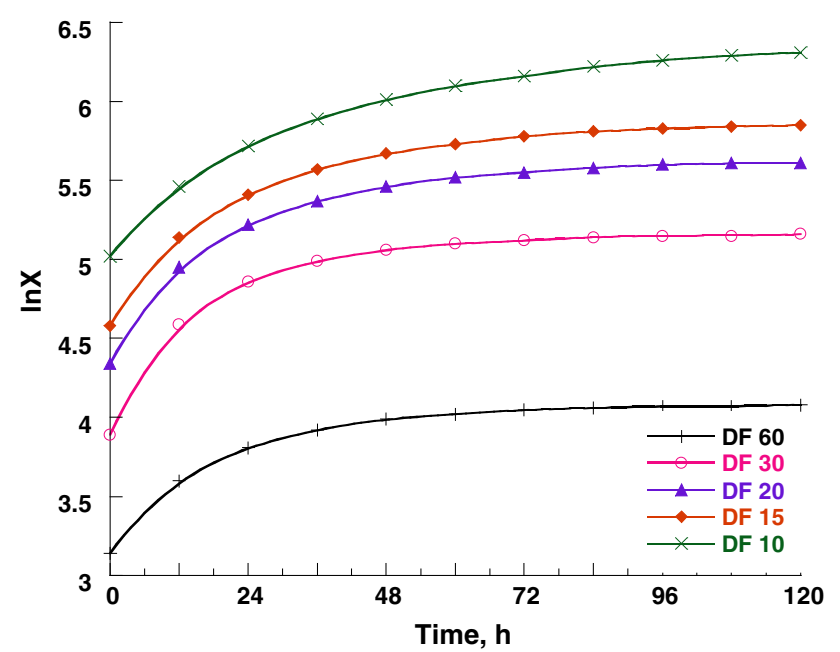

Fig. $6 \ln X$ vs. $t$ plot for different dilutions (Each curve corresponds to that in Fig. 5 with the same DF)

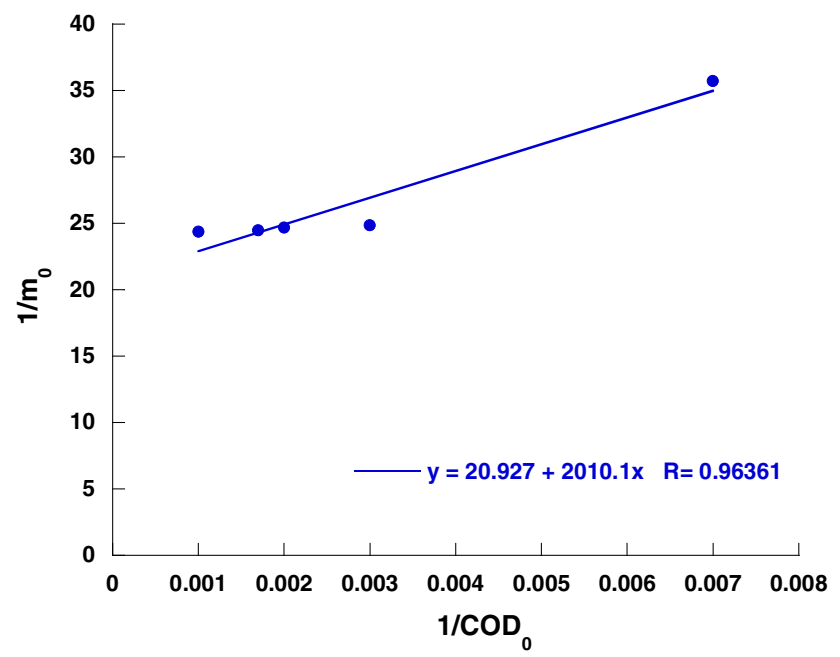

Fig. $71 / m_{0}$ vs. $1 / \mathrm{COD}_{0}$ plot

using literature data acquired under different conditions) in the design of the treatment plant, and the design parameters are expected to be more appropriate for functioning.

\section{Conclusions}

A low cost respirometric device called 'BMRS' has been designed and fabricated, which can be used for different purposes such as (1) monitoring of biodegradation process in wastewater, (2) alternative to BOD test providing equivalent information (3) calculating respiratory quotient and (4) study of microbial growth kinetics and routine determination of biokinetic coefficients. Data treatment for oxygen consumption and carbon dioxide generation in a biodegradation process has been presented by a simple calculation method. The device would provide more precise information about oxygen uptake in a system than the conventional BOD method does. The performance of the device is quite satisfactory and it is concluded that the present respirometer is a simple and cost-effective nondigital wastewater monitoring device, which could be used in the academic research as well as in industrial applications in developing countries.

Acknowledgments This study has been supported partially by the research grants of Shahjalal University of Science and Technology and the University Grants Commission (UGC project "STUDY ON THE BIODEGRADABILITY OF INDUSTRIAL WASTEWATER USING RESPIROMETER"). M.S. Rahman acknowledges NSICT fellowship awarded by Ministry of Science and Technology, Government of Bangladesh.

Open Access This article is distributed under the terms of the Creative Commons Attribution License which permits any use, distribution, and reproduction in any medium, provided the original author(s) and the source are credited.

\section{References}

Aiba S, Furuse H (1990) Some comments on respiratory quotient (RQ) determination from the analysis of exit gas from a fermentor. Biotechnol Bioeng 36(5):534-538

APHA (2005) Standard methods for examination of water and wastewater, 21st edn. APHA, AWWA, WPCF, Washington

ASAP (2012) Direct measurement of respiratory quotient (RQ) in fermentation processes. Distelweg $80 \mathrm{M} \bullet 1031 \mathrm{HH}$ Amsterdam, P.O. box $37146 \bullet 1030$ AC Amsterdam

Atkinson CF, Jones DD, Gauthier JJ (1997) Microbial activities during composting of pulp and paper-mill primary solids. World J Microbiol Biotechnol 13:519-525

Chiil K, Eun KC, In-Soung C (2008) Non-steady state estimation of biodegradability of dyeing wastewater using respirometer. Korean J Chem Eng 25:553-557

Choung YK, Kim HS, Yoo SI (1999) Estimation of biokinetic parameter of heterotrophic biomass using oxygen uptake rate. environmental modeling. In: Proceedings of the international conference on water, environment, ecology, socio-economics and health engineering (Weeshe), Seoul National University, Seoul, Korea

Contreras EM, Bertola NC, Giannuzzi L, Zaritzky NE (2002) A modified method to determine biomass concentration as COD in pure cultures and in activated sludge systems. Water SA 28:463-468

Dilly O (2001) Microbial respiratory quotient during basal metabolism and after glucose amendment in soils and litter. SoilBiol Biochem 33:117-127

Dilly O (2003) Regulation of the Respiratory Quotient of Soil Microbiota by Availability of Nutrients. FEMS Microbiol Ecol 43:375-381

Doble M, Gummadi SN (2007) Biochemical engineering. PrenticeHall of India Private Limited, New Delhi

DOE (2008) Guide for assessment of effluent treatment plants. Ministry of Environment and Forest, Bangladesh

Edgardo MC, Albertario ME, Bertola NC, Zaritzky NE (2008) Modeling phenol biodegradation by activated sludges evaluated through respirometric techniques. J Hazard Mater 158:366-374 
Franzén CJ, Albers E, Niklasson C (1996) Use of the inlet gas composition to control the respiratory quotient in microaerobic bioprocesses. Chem Eng Sci 51:3391-3402

Genc N, Yonsel (2007) Evaluation by respiration measurements (OTR, CTR and RQ) of the biological activity in sludge digestors operated under microaerobic conditions. Chem Biochem Eng 21(2):163-168

Ghosh TK, Moitra A, Kunwar GK (1985) Bimodal oxygen uptake in a freshwater air breathing fish, Notopterus chitala. Jpn J Ichthyol 33(3):280-285

Grady C, Dang J, Harvey D, Jobbagy A, Wang XL (1989) Determination of biodegradation kinetics through use of electrolytic respirometer. Water Sci Technol 21:957-968

Hill JB, Bleam RD, Zitrides TG (1998) Diagnosing the biomass. N J Effl 30-36 http://www.njwea.org/

Ince M, Yildiz F, Engin GO, Engin SN, Keskinler B (2008) Respirometric kinetic parameter calculations of a batch jet loop bioreactor treating leachate and oxygen uptake rate estimation by DTM. J Hazard Mater 153:991-998

Jowett M (1928) Note on the calibration of Barcroft manometers. Biochem J 22:717-719

Kessick MA (1976) The calibration of closed-end manometric biochemical oxygen demand respirometers. Biotechnol Bioeng 18(4):595-598

Khan MS, Ahmed S, Evans AEV, Chadwick M (2009) Methodology for performance analysis of textile effluent treatment plants in Bangladesh. Chem Eng Res Bull 13:61-66

Kim IS, Park W (2005) Respirometric monitoring for the determination of effective height and reaction rate constant in up-flow autotrophic denitrification reactor packed with sulfur. Environ Monit Assess 104:221-234

Kim I, Young JC, Kim S, Kim S (2001) Development of monitoring methodology to finger print the activated sludge processes using oxygen uptake rate. Environ Eng Res 6(4):251

Kovács RF, Házi Z, Csikor Z, Miháltz P (2007) Connection between oxygen uptake rate and carbon dioxide evolution rate in aerobic thermophilic sludge digestion. Period Polytech Chem Eng 51(1):17-22

Kovar KK, Egli T (1998) Growth kinetics of suspended microbial cells: from single-substrate-controlled growth to mixed-substrate kinetics. Microbiol Mol Biol Rev 62:646-666

Kuyen YL, Yuebo BZ (1996) Oxygen transfer limitation in a respirometer. Water Environ Res 68:36-41

Lee EW, Oswald WJ (1954) Comparative studies of the dilution and Warburg methods for determining BOD. Sew Ind Wastes 26:1097-1108

Logan BE, Wagenseller GA (1993) The HBOD test: a new method for determining biochemical oxygen demand. Water Environ Res 65:862-868

Mahendraker V, Viraraghavan T (1995) Respirometry in environmental engineering. J Environ Sci Heal A30:713-734

Marsili LS, Tabani F (2002) Accuracy analysis of a respirometer for activated sludge dynamic modeling. Water Res 36:1181-1192

Metcalf, Eddy (2005) Wastewater engineering: treatment, disposal, and reuse. McGraw-Hill, New York

Min B, Kohler D, Logan BE (2004) A simplified headspace biochemical oxygen demand test protocol based on oxygen measurements using a fiber optic probe. Water Environ Res
76:29-36

Mitz SV, Newman ME (1988) Allometric relationship between oxygen consumption and body weight of mosquitofish, Gambusia ajjinis. Env Biol Fish 24(4):267-273

Panda H (2011) The complete guide on industrial pollution control. Asian pacific business press Inc., India

Park JK, Wang J, Novotny G (1997) Wastewater characterization for evaluation of biological phosphorus removal. Research report 174, Wisconsin department of natural resources, Madison, WI. http://digital.library.wisc.edu/1711.dl/EcoNatRes.DNRRep174/

Perkins J (1943) Barcroft-Warburg manometric apparatus-usage, recent developments, and applications. Ind Eng Chem Anal Ed 15:61-68

Rahman MS, Islam MA (2013) Application of a multichannel respirometer to assess the biokinetic parameters of industrial wastewater. Int Res J Environ Sci 2(6):71-75

Rahman MS, Islam MA, Habib S, Sarker J (2013) Measuring biodegradability of industrial wastewater by a low-cost differential respirometer. Res J Eng Sci 2:1-4

Ramalho RS (1977) Introduction to wastewater treatment process. Laval University, Academic press, Quebec, London

Roppola K (2009) Environmental applications of manometric respirometric methods. Ph.D Dissertation, University of Oulu, Finland. http://herkules.oulu.fi/isbn9789514290794.pdf/

Rozich AF, Gaudy AF (1992) Design and operation of activated sludge process using respirometry. Lewis Publishers, Boca Raton

Sawyer CM, Nichols MS (1939) Respiratory quotient of activated sludge and of activated sludge-sewage mixtures. Ind Eng Chem 31(8): 1042-1047

Sultana Z, Ali ME, Uddin MS, Haque MM (2013) Implementation of effluent treatment plants for wastewater treatment. J Environ Prot 4:301-308

Tzoris A, Hall EAH (2006) Rapid detection of toxicity in wastewater: recent developments with manometric respirometry. Anal Chim Acta 573-574:147-157

Vanrolleghem P (2002) Principles of respirometry in activated sludge wastewater treatment. In: Proceedings of the international workshop on recent development in respirometry for wastewater treatment plant monitoring and control. Taipei, Taiwan

Wenxiang X, Jincheng L, Xilai Z (2008) Biodegradability assessment of industrial wastewater by Warburg respirometer. In: The 2nd international conference on bioinformatics and biomedical engineering, 3738-3740

Wu YS, Chiang CF, Lu CJ (2004) Respirometric evaluation by graphical analysis for microbial systems. Environ Monit Assess 92:137-152

Yoong ET, Lant PA, Greenfield PF (2000) In situ respirometry in an SBR treating wastewater with high phenol concentrations. Water Res 34:239-245

Young JC, Cowan RM (2004) Respirometry for environmental science and engineering. SJ Enterprises, USA

Zeng AP, Byun TG, Posten C, Deckwer WD (1994) Use of respiratory quotient as a control parameter for optimum oxygen supply and scale-up of 2,3-butanediol production under microaerobic conditions. Biotechnol Bioeng 44(9):1107-1114 